\title{
Farewell and Welcome
}

\author{
Irene Heim ${ }^{1} \cdot$ Angelika Kratzer ${ }^{2}$
}

Accepted: 28 October 2021 / Published online: 12 November 2021

(C) The Author(s), under exclusive licence to Springer Nature B.V. 2021

We are overjoyed to announce that, after 30 years, we have passed on the editorship of Natural Language Semantics to Amy Rose Deal. This is the last issue under our editorship. Amy Rose represents everything Natural Language Semantics has stood for. The appearance of Natural Language Semantics in 1992 marked the coming of age of formal semantics as a linguistic discipline. From the very beginning to the present day, the focus of the journal has been on advancing semantic theory by investigating linguistic phenomena in a diverse range of languages. By encouraging crosslinguistic work at the interface between syntax and semantics, the journal played an important role in connecting formal semantics with generative syntax as it had emerged from Chomsky's 1981 Pisa Lectures. Over the years, the journal has also become known for setting the standards for how to do theory-driven, fieldwork-based, semantic research on underdescribed languages.

Christine Bartels has been the manuscript editor for the journal from the very beginning and has contributed so much to its success, working with authors on every aspect of their papers and seeing them through the production process. We don't know where the journal would be without her. Thank you, Christine!

Publisher's Note Springer Nature remains neutral with regard to jurisdictional claims in published maps and institutional affiliations.

$\triangle$ I. Heim

A. Kratzer

1 MIT, Cambridge, MA, USA

2 University of Massachusetts, Amherst, MA, USA 